\title{
Fabrication of WC-TiC-Co Cemented Carbide at Different Heating Rate by Micro-FAST process
}

\author{
Yitong Chen, Yi Yang, Gang Yang, Libo Wang, Mingxia Wu ${ }^{*}$ \\ School of Manufacturing Science and Engineering, Sichuan University, Chengdu, 610065, P.R. China
}

\begin{abstract}
As demands on miniature products increase significantly, a rapid prototyping and production system for highly flexible and cost-efficient production of micro components made from a wide range of materials is needed. In present work, the Micro-forming Fields Activated Sintering Technology (Micro-FAST) with the coupling effects of electrical and pressure fields as the dominant driving force, has been proved to be very successful in the fabrication of the nearly full-density micro-cylinder parts from WC-8Co-xTi- $\mathrm{nC}$ powders $(\mathrm{x}=4, \mathrm{n}=2$ or $\mathrm{x}=6, \mathrm{n}=0)$. The influence of heating rate and composition of titanium and carbon has been investigated. Based on the analysis of the relative density, microstructure and mechanical properties, high density (up to $99.7 \%$ ), fine grain sizes and good mechanical properties could be obtained by MicroFAST to sinter WC-TiC-Co Cemented Carbide bodies under a low sintering temperature $\left(1200{ }^{\circ} \mathrm{C}\right)$.
\end{abstract}

Keywords: Rapid prototyping Sintering Micro structure Micro-FAST

\section{Introduction}

Cemented carbide is usually an alloy material prepared by powder metallurgy from a carbide powder of high hardness refractory metal such as WC and TiC and the metal such as $\mathrm{Co}, \mathrm{Fe}, \mathrm{Ni}$ or their compound". Due to its high hardness, strength and excellent wear-resistance and corrosion resistance, the traditional tungsten-cobaltbased cemented carbide has been widely used in cutting tools, wear-resistant parts and mining materials and other fields $^{[2+1}$. Nevertheless, it also exists problems such as a relatively short life span, working softening and other issues.

The hardness and wear-resistance of WC-TiC-Co alloy are generally better than that of WC-Co cemented carbide due to the hardness and wear-resistance of titanium carbide is higher than that of tungsten carbide. Compared with the WC-Co based cemented carbide, the WC-TiC-Co cemented carbide the flexural strength decreases with increasing temperature to a lesser extent ${ }^{\text {ts }}$. Therefore, WC-TiC-Co cemented carbide is prepared, which can solve the problems of working softening, short life span and poor red hardness in practical applications ${ }^{(\cdot 9)}$.

The cemented carbide manufactured by the traditional sintering process usually requires a higher sintering temperature and longer sintering period. Prolonged sintering at high temperatures leads to the growth of grain size of the main phase, which seriously affects the further improvement of the properties of the sintered sample. Therefore, development of a new sintering technique with a lower sintering temperature and shorter sintering period, is needed. K. Feng ha.in have achieved the reaction of combustion synthesis by activating $\mathrm{Fe}-\mathrm{Ti}-\mathrm{C}$ system in electric field.

In this work, a newly developed method, named as Micro-FAST (Micro- forming Fields Activated Sintering Technology), based on the coupling effect of electric and force fields, offers a promising new route for fabricating the cemented carbide. The process (Micro-FAST) uses low voltage and high current, pressure-assisted sintering and synthesis technique, which has been used recently in materials processing ${ }^{[2,1,3]}$.

In this paper, Micro-FAST was carried out to fabricate the WC-TiC-Co cemented carbide, by adding a certain amount of titanium powder and carbon powder in the raw WC-8Co powder. The effect of the different heating rate during the process of sintering of WC-8Co-xTi$\mathrm{nC}(\mathrm{x}=4, \mathrm{n}=2$ or $\mathrm{x}=6, \mathrm{n}=0)$ in multiple physical fields was investigated, which have been prove to play a critical role in affecting the densification process.

\section{Experimental Method}

The chemical compositions of cermets in this work were given in Table 1. The characteristics of the starting powders used in the experiment were listed in Table 2. Raw powders were mixed in a planetary ball-mill for 2 hours at a speed of $400 \mathrm{rpm}$ with a ceramic ball-to powder ratio of $5: 1$.

Table 1. Chemical compositions of WC-Ti-C-Co powders

\begin{tabular}{|l|c|c|c|c|}
\hline Cermets & WC & Ti & C & Co \\
\hline
\end{tabular}

Corresponding author: wumingxia@scu.edu.cn 


\begin{tabular}{|c|c|c|c|c|}
\hline $\mathrm{W} 1$ & 86 & 4 & 2 & 8 \\
\hline $\mathrm{W} 2$ & 86 & 6 & 0 & 8 \\
\hline
\end{tabular}

Table 2. Characteristics of the raw powders

\begin{tabular}{|c|c|c|}
\hline Powder & $\begin{array}{c}\text { Particle Size } \\
(\mu \mathrm{m})\end{array}$ & Chemical composition (wt.\%) \\
\hline WC & 0.6 & $\begin{array}{r}\text { T.C:5.92, F.C: } 0.030, \text { O: } 0.15, \\
\mathrm{Cr}_{3} \mathrm{C}_{2}: 0.50\end{array}$ \\
\hline $\mathrm{Ti}$ & 40 & C:0.02, O:0.35, others: 0.1 \\
\hline $\mathrm{C}$ & 30 & others: 0.1 \\
\hline $\mathrm{Co}$ & 2 & C: 0.015, O: 0.4, others: 0.002 \\
\hline
\end{tabular}

The sintering process, as shown in Figure 1, was carried out in a Gleeble-1500D thermal simulation instrument. An approximate amount of raw powder was directly placed onto a $4 \mathrm{~mm} \times 4 \mathrm{~mm}$ graphite die. Sintering was started when the vacuum pressure reached 10-3 Pa. A thermocouple device situated on the die wall, was used to measure and adjust the temperature. A summary of the detailed sintering parameters were given in Table 3 .

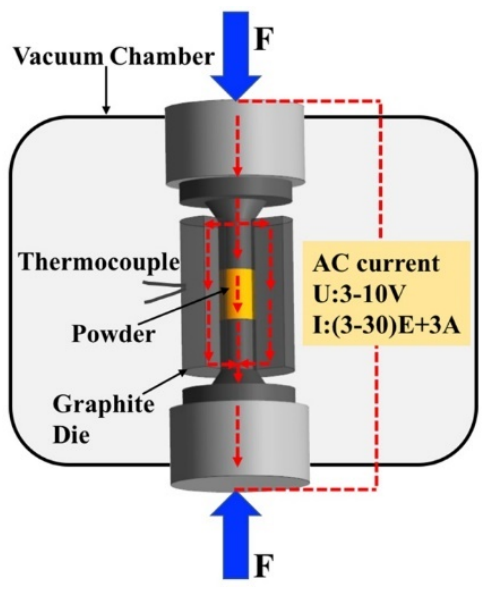

Fig. 1. Schematic diagram of sintering process

Table 3. Processing parameter of the experiment

\begin{tabular}{|c|c|c|c|c|}
\hline Powder & $\begin{array}{c}\text { Heating } \\
\text { Rate } \\
\left({ }^{\circ} \mathrm{C} / \mathrm{s}\right)\end{array}$ & $\begin{array}{c}\text { Sintering } \\
\text { Temperature } \\
\left({ }^{\circ} \mathrm{C}\right)\end{array}$ & $\begin{array}{c}\text { Pressure } \\
(\mathrm{MPa})\end{array}$ & $\begin{array}{c}\text { Holdin } \\
\mathrm{g} \text { Time } \\
(\mathrm{min})\end{array}$ \\
\hline $\mathrm{W} 1$ & 25 & 1200 & 75 & 12 \\
\hline $\mathrm{W} 1$ & 50 & 1200 & 75 & 12 \\
\hline $\mathrm{W} 1$ & 75 & 1200 & 75 & 12 \\
\hline $\mathrm{W} 1$ & 100 & 1200 & 75 & 12 \\
\hline $\mathrm{W} 2$ & 25 & 1200 & 75 & 12 \\
\hline
\end{tabular}

\begin{tabular}{|c|c|c|c|c|}
\hline W2 & 50 & 1200 & 75 & 12 \\
\hline W2 & 75 & 1200 & 75 & 12 \\
\hline W2 & 100 & 1200 & 75 & 12 \\
\hline
\end{tabular}

The density of sintered samples was measured by the Archimedes' method, where each value was checked for at least three times in order to eliminate artificial inaccuracy. Microstructure of polished specimens was observed by SEM (Hitachi S-3000N) in BSE mode coupled with EDS (HORIBA EX-320). Phase identification was carried out by XRD (Rigaku Ultima IV). Hardness was measured using HV-50A Vickers hardness meter. Fracture toughness $\left(\mathrm{K}_{\mathrm{c}}\right)$ was calculated from Vickers hardness, which was examined by indention method under load of $30 \mathrm{~kg}$, following the equation

$K_{I C}=0.15 \sqrt{\frac{\mathrm{H} V_{30}}{\sum_{i=1}^{4} l_{i}}}$

Where $\mathrm{HV}_{30}$ is the Vickers hardness $\left(\mathrm{N} / \mathrm{mm}^{2}\right)$, li is the length of the crack tip from the hardness indent (mm).

\section{Results and discussion}

\subsection{Phase characterization}

The XRD patterns of sintered samples with different heating rates are shown in Fig. 2. Only the diffraction peaks of $\mathrm{WC}$ and $\mathrm{TiC}$ were detected, implying that the $\mathrm{TiC}$ was generated by $\mathrm{C}$ and $\mathrm{Ti}$ reactions in raw powder during the sintering process. As the point of thermodynamic analysis, it shows that the free $\mathrm{C}$ in WC can be easier to combine with $\mathrm{Ti}$, which can become $\mathrm{TiC}$ phase.

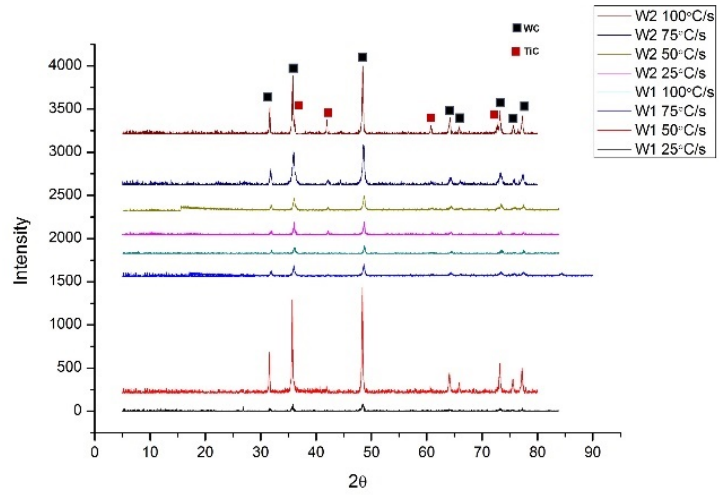

Fig. 2. XRD of samples under different holding times

\subsection{Microstructure}

The microstructures of sintered samples were observed by SEM in BSE mode. As shown in Fig.3, Although the cermets show similar core-rim structure, it can be seen that there are some gradual changes in the microstructure with different heating rate as shown in Fig. 3 . It shows that with the inner rim increases with the 
increasing of heating rate. The core-rim structures are more obvious with the increasing heating rate, especially, when the heating rates were $75^{\circ} \mathrm{C} / \mathrm{s}$ and $100^{\circ} \mathrm{C} / \mathrm{s}$. Because the lower the heating rate is, the more thoroughly the titanium grains and carbon grains of the samples are combined, forming a $\mathrm{TiC}$ dark phase. When the heating rate of the sample is accelerated, the titanium powders and the carbon powders are underreaction, and the samples appear core-rim structure.

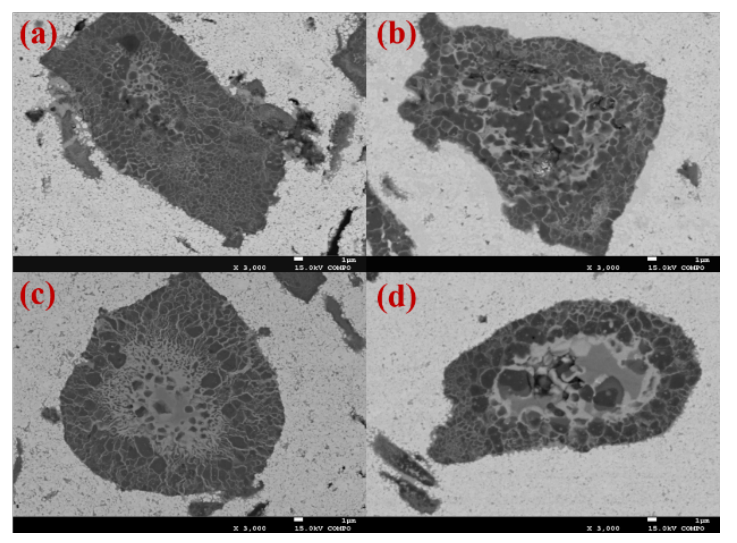

Fig. 3. BSE micrograph of $\mathrm{W} 1$ at different heating rate,

(a) $25^{\circ} \mathrm{C} / \mathrm{s}$, (b) $50^{\circ} \mathrm{C} / \mathrm{s}$, (c) $75^{\circ} \mathrm{C} / \mathrm{s}$, (d) $100^{\circ} \mathrm{C} / \mathrm{s}$

Fig. 4 is an image of W1(WC-8Co-6Ti) sintered with a heating rate of $50^{\circ} \mathrm{C} / \mathrm{s}$. The EDS results of $\mathrm{WC}-8 \mathrm{Co}-6 \mathrm{Ti}$ cermets are shown in Table 4. According to the atomic ratio of energy spectrum, the region 1 is a typical $\mathrm{WC}-\mathrm{Co}$ phase matrix, the region 2 is mainly $(\mathrm{W}, \mathrm{Ti}) \mathrm{C}$ phase and $\mathrm{TiC}$ phase. It is showed that $\mathrm{Ti}$ atoms replace the $\mathrm{W}$ atoms in $\mathrm{WC}$, forming $(\mathrm{W}, \mathrm{Ti}) \mathrm{C}$ phase, at the same time, it is accompanied by the formation of the $\mathrm{TiC}$ phase during the WC-8Co-6Ti sintering.

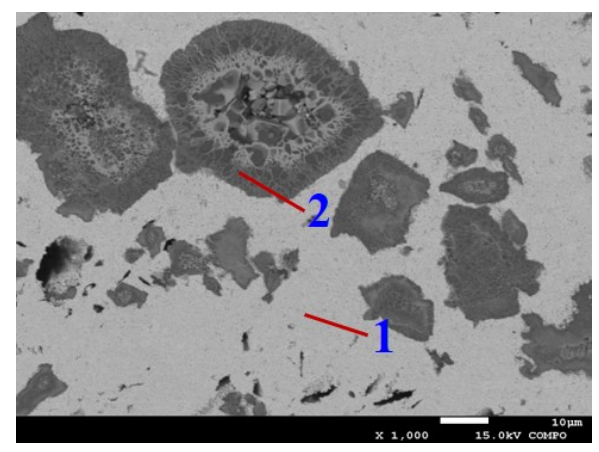

Fig. 4. BSE image of W1 sample sintered with a heating rate of $50^{\circ} \mathrm{C} / \mathrm{s}$

Table 4. EDS analysis of W1 sample sintered with a heating rate of $50^{\circ} \mathrm{C} / \mathrm{s}$ (at.\%)

\begin{tabular}{|c|c|c|}
\hline Element & Region 1 & Region 2 \\
\hline $\mathrm{C}$ & 66.23 & 58.53 \\
\hline $\mathrm{Ti}$ & 0 & 27.67 \\
\hline
\end{tabular}

\begin{tabular}{|c|c|c|}
\hline Co & 5.50 & 0.92 \\
\hline $\mathrm{W}$ & 28.27 & 12.88 \\
\hline
\end{tabular}

Fig. 4 is an image of WC-8Co-4Ti-2C sintered with a heating rate of $50^{\circ} \mathrm{C} / \mathrm{s}$. The EDS results of WC-8Co-4Ti$2 \mathrm{C}$ cermets are shown in Table 5 . According to the atomic ratio of energy spectrum, it is known that the region 1 is the typical WC-Co phase matrix. Region 2 the atomic ratio of $\mathrm{W}+\mathrm{Ti}$ to $\mathrm{C}$ is roughly $1: 1$, which is mainly $(\mathrm{W}, \mathrm{Ti})$ $\mathrm{C}$ phase, and some $\mathrm{TiC}$ phase. It is showed that $\mathrm{Ti}$ atoms replace a small fraction of $\mathrm{W}$ atoms in $\mathrm{WC}$.

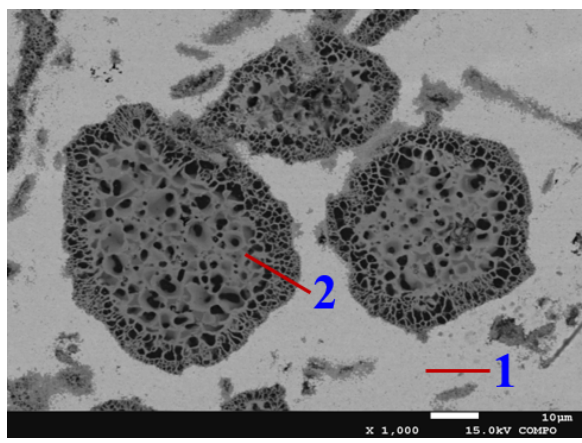

Fig. 5. BSE image of W2 sample sintered with a heating rate of $50^{\circ} \mathrm{C} / \mathrm{s}$

Table 5. EDS analysis of W1 sample sintered with a heating rate of $50^{\circ} \mathrm{C} / \mathrm{s}$ (at.\%)

\begin{tabular}{|c|c|c|}
\hline Element & Region 1 & Region 2 \\
\hline $\mathrm{C}$ & 64.03 & 35.13 \\
\hline $\mathrm{Ti}$ & 0 & 47.36 \\
\hline $\mathrm{Co}$ & 2.50 & 0 \\
\hline $\mathrm{W}$ & 30.27 & 17.51 \\
\hline
\end{tabular}

\subsection{Mechanical properties}

Fig. 6, Fig. 7 and Fig. 8 shows hardness, fracture toughness and relative densities of the sintered samples. Compared with the hardness, fracture toughness and relative density, it peaks at $50 \mathrm{C} \%$. Due to the heating rate increasing, the core-rim structure of $\mathrm{TiC}$ phases and (W,Ti)C phases substitute the single TiC phase, which brings better mechanical properties. Furthermore, with the heating rate increasing, the titanium grains and the carbon grains are underreaction, and the core-rim structure has poor connection with WC-Co matrix. Therefore, the mechanical properties of the samples are reduced when the heat rate is high.

The mechanical properties of WC-8Co-6Ti samples are better than that of WC-8Co-4Ti-2C samples both in hardness and fracture toughness. Compared with WC8Co-4Ti-2C, WC-8Co-6Ti has less TiC phases and more 
(W, Ti) C phases. (W, Ti) $\mathrm{C}$ phase has higher modulus of elasticity than $\mathrm{TiC}$ phase, which can prevent crack propagation and enhance ceramic toughness.

When sintering is carried out under an electrical field, the rapid heating rate can enhance mass transport by electromigration, which contributes significantly to the remarkable increase in neck growth because the highest density of current passing through the particles could generate larger Joule heating and induce a local high temperature. And it may promote the atomic diffusion. And rapid heating rate can decrease the soaking time and inhibition of coarse grains. However, the heating rate is too high, instant high temperature of the samples may result in coarse grains and reduce performance.

As a result, $50 \mathrm{C} \% \mathrm{~s}$ is the best heating rate to fabricate the WC-TiC-Co samples.

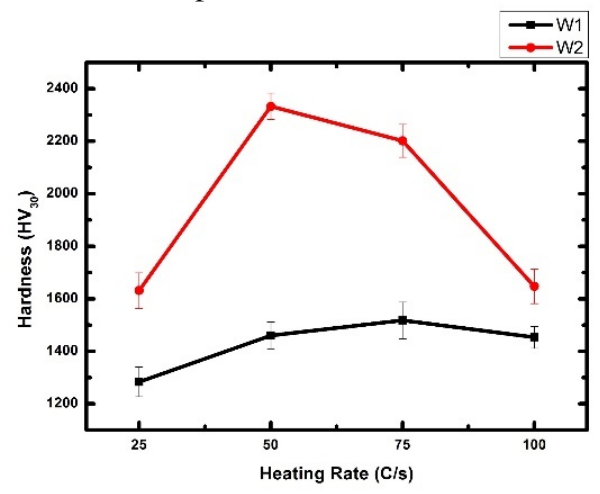

Fig. 6. Hardness of the samples with different heating rate

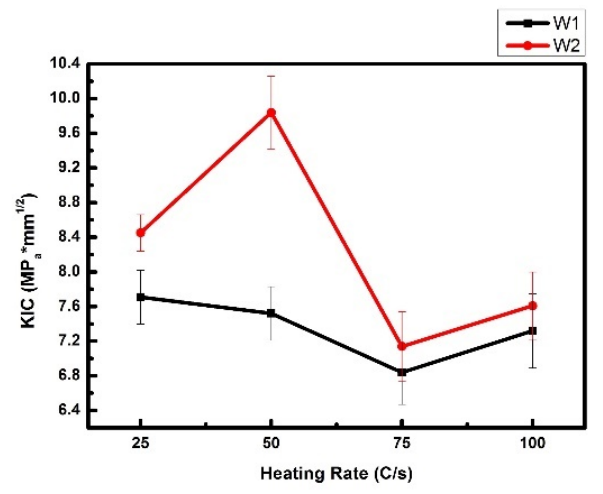

Fig. 7. Fracture toughness of the samples with different heating rate

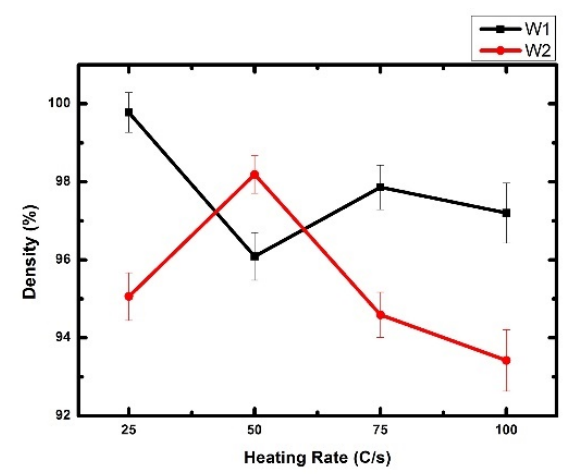

Fig. 8. Density of the samples with different heating rate

\section{Conclusion}

In summary, we successfully fabricated the nearly full-density $(99.70 \%)$ micro WC-TiC-Co parts from raw powders using the Micro-FAST technique. With the increasing of heating rate, the hardness, fracture toughness and density almost present a tendency to increase and then decrease. The results show that $50 \mathrm{C} \% \mathrm{~s}$ is the optimal heating rate to fabricate the WC-TiC-Co samples. And the mechanical properties of WC-8Co-6Ti samples are better than that of $\mathrm{WC}-8 \mathrm{Co}-4 \mathrm{Ti}-2 \mathrm{C}$ samples, which probably because of the content of $\mathrm{TiC}$ and $(\mathrm{W}, \mathrm{Ti})$ $\mathrm{C}$ phases. In the future work, Micro-FAST will be used to prepare the metal matrix composites and and promote the real engineering applications of this new technique.

\section{Acknowledgements}

This work was supported by the Natural Science Foundation of China (Grand numbers 51675357 and 51575369). And the author Mingxia Wu thanks the support of Sichuan University post-doctoral research and development fund (2018SCU12067).

\section{References}

1. G. S. Upadhyaya. Mater. Des. 22, 6 (2001)

2. V. Bounhoure, S. Lay, S. Coindeau, S. Norgren, E. Pauty. Int. J Refract. Met. Hard Mater. 52 (2015)

3. W. Su, Y. Sun, J. Feng, J. Liu, J. Ruan. Int. J Refract. Met. Hard Mater. 48, 6 (2015)

4. M. R. Rumman, Z. Xie, S. J. Hong, R. Ghomashchi. Mater. Des. 68 (2015)

5. P. Feng, W. Xiong, L. Yu, Y. Zheng, Y. Xia. J. Ruan. Int. J Refract. Met. Hard Mater. 22 (2004)

6. W. M. Merchan, A.V. Saveliev, L.A. Kennedy. Carbon 42, 3 (2004)

7. S. P. Chen, Q. S. Meng, J. F. Zhao, Z. A. Munir. J. Alloys Compd. 476,1 (2009)

8. Z. A. Munir. Mater. Sci. Eng. A 287, 2 (2000)

9. G. Jiang, H. Zhuang, W. Li. Scr. Mater. 50, 8 (2004)

10. K. Feng, Y. Yang, B. Shen, H. Lin, H. He. Rare Metal Mater. Eng.34, 3 (2005)

11. Y. Yang, K. Q. Feng, K. Z. Shen, H. He. Rare Metal Mater. Eng. 34, 4 (2005)

12. D. Lu, Y, Yang, Y. Qin, G, Yang. J. Microelectromech. 22 (2013)

13. M. X. Wu, G. Yang, J. Liu, D. Q. Yin, Y. Yang. J. Alloys Compd. 692 (2017)

14. W. D. Schubert, H. Neumeister H, G. Kinger, B. Lux. Int. J Refract. Met. Hard Mater.16 (1998) 